\title{
ОСОБЕННОСТИ ПРАВОВОГО РЕГУЛИРОВАНИЯ БАНКОВСКОЙ ДЕЯТЕЛЬНОСТИ В УСЛОВИЯХ БОРЬБЫ С ПАНДЕМИЕЙ COVID-19
}

\section{FEATURES OF LEGAL REGULATION OF BANKING ACTIVITIES IN THE CONTEXT OF COMBATING THE COVID-19 PANDEMIC \\ V. Terekhova}

Summary. The article analyzes the problematic aspects of the implementation of banking legislation in the context of combating the COVID-19 pandemic, reveals the main measures taken by the state to stabilize the financial (in particular, banking) system of the Russian Federation, as well as measures to maintain financial stability of both significant sectors of the state, as well as individuals and businesses.

Keywords: credit holidays, state support measures, Bank of Russia, small and medium-sized businesses, individual entrepreneurs.
B связи с обострившейся ситуацией в стране, в российском законодательстве произошел ряд изменений, в том числе изменения коснулись и банковской сферы. Были реструктуризированы кредиты заемщикам, введены кредитные каникулы и многое другое. Кроме того, был введен пониженный коэффициент риска в размере 70\% вместо 100\% для рублевых кредитов компаниям, производящим лекарства и медицинскую технику.

Кредитные каникулы были введены как мера помощи для населения в связи со сложной ситуацией. Тысячи представителей малого и среднего бизнеса, а также индивидуальные предприниматели приостановили на время ограничительных мероприятий свою деятельность, вследствие этого и они, и многие россияне лишились доходов, а значит, возможности погашать платежи по кредитам. Решения Президента Российской Федерации и Правительства дадут физическим лицам и предпринимателям возможность на время приостановить выплаты кредитным организациям [1].

Кредитные каникулы представляют собой банковский продукт, который подразумевает предоставление отсрочки по ежемесячным платежам. Они устанавливаются на определенный срок по заявлению от заемщика. Необходимость в таких каникулах нужно доказать.
Терехова Валентина Владимировна К.ю.н., дочент, Российский государственный гуманитарный университет (РГГУ), г. Москва wsamoilova@mail.ru

Аннотация. В статье анализируются проблемные аспекты реализации банковского законодательства в условиях борьбы с пандемией COVID-19, раскрываются основные меры, принимаемые государством в целях стабилизации финансовой (в частности банковской) системы Российской Федерации, а также меры по поддержанию финансовой стабильности как значимых отраслей деятельности государства, так и физических лиц, и субъектов предпринимательства.

Ключевые слова: кредитные каникулы, государственные меры поддержки, Банк России, малый и средний бизнес, индивидуальные предприниматели.

Ни один банк не даст даже самому добросовестному клиенту каникулы просто так. В качестве доказательства можно использовать любой документ, подтверждающий резкое снижение дохода более чем на $30 \%$.

Президент Российской Федерации Владимир Владимирович Путин в ходе обращения к гражданам Российской Федерации, которое было 25 марта, предложил ввести каникулы по ипотечным и потребительским кредитам. Если доход гражданина снизился на $30 \%$ и более, то он должен иметь право приостановить, на время введенного режима самоизоляции, выплаты банкам, пролонгировав долговые обязательства. Путин В.В. сообщил, что такой механизм будет действовать и для индивидуальных предпринимателей, а также представителей малого и среднего бизнеса. При этом, президент уточнил, что не должны применяться к заемщикам какие-либо необоснованные штрафные санкции, закрепленные банковским законодательством по вопросам неисполнения должником своих обязательств перед кредитором.

Максимальная сумма кредита, для которого действует отсрочка, такова:

- 250000 руб. потребительский кредит для физических лиц и 300000 руб. для индивидуальных предпринимателей; 
- максимальная сумма ипотечного кредита составляет 2000000 руб. для всех регионов (исключение: Москва - 4500000 руб., Московская область, г. Санкт-Петербург и субъекты РФ Дальневосточного федерального округа - 3000 000 руб.);

- 600000 руб.- оформленный заемщиком автокредит;

- по кредитной карте лимит не может превышать 100000 руб.

Размеры кредитов утвердило правительство России. Для того, чтобы банк предоставил кредитные каникулы необходимо соблюсти ряд условий:

- размер займа (ипотека или потребительский кредит) не превышает нормативы, которые установило правительство;

- у заемщика из-за пандемии коронавируса существенно снизились доходы по сравнению со среднемесячными показателями за 2019 год (30\% и более);

- кредитный договор оформлен до апреля текущего года, то есть до вступления закона в силу;

- гражданин или ИП, обращающиеся за временным послаблением по кредиту, в это время не пользуются другим льготным периодом (например, ипотечными каникулами).

Постановлением Правительства от 03.04.2020г № 435 установлен лимит по сумме на кредитные каникулы только для индивидуальных предпринимателей, юридические же лица не ограничены по сумме. Но, индивидуальный предприниматель, при этом, может требовать и отсрочку исполнения своих обязательств и уменьшения ежемесячных платежей по кредитам.

Этим же Постановлением закреплен перечень направлений деятельности юридических лиц, при условии осуществления которых, им будут предоставлены кредитные каникулы.

Кроме того, установленные лимиты по сумме для кредитных каникул могут быть изменены, в сторону увеличения, на региональном уровне.

Перечень документов для предоставления кредитных каникул законодатель упростил до 1 документа, а именно - письма о предоставлении кредитных каникул. При этом, положения статьи 6 Федерального закона от 03.04.2020 г. № 106-Ф3 «О внесении изменений в Федеральный закон «О Центральном банке Российской Федерации (Банке России)» и отдельные законодательные акты Российской Федерации в части особенностей изменения условий кредитного договора, договора займа» [2], предусматривают предоставление справки для бан- ка о кредитных каникулах (2-НДФЛ за 2019 и 2020гг), выписка из реестра (в сфере занятости населения) и больничный лист. Этот перечень необходимо предоставить для обоснования требования по кредитным каникулам.

Правительство Российской Федерации утвердило правила предоставления субсидий из федерального бюджета российским кредитным организациям на возмещение недополученных ими доходов по кредитам, выданным в 2020 году субъектам малого и среднего предпринимательств на неотложные нужды для поддержания и сохранения занятости. Под неотложными нуждами для поддержания и сохранения занятости понимаются документально подтвержденные расходы, связанные с выплатой заработной платы и обязательными начислениями на нее. Данные правила регламентируют порядок предоставления, условия и требования, которым должна соответствовать кредитная организация для получения субсидий, так, например, одним из требований является наличие кредитного рейтинга не ниже уровня «A-(RU)» по национальной рейтинговой шкале для Российской Федерации и (или) кредитного рейтинга не ниже уровня «ruA-» по национальной рейтинговой шкале для Российской Федерации либо поручительства акционерного общества «Федеральная корпорация по развитию малого и среднего предпринимательства» [3].

Также Центральным Банком Российской Федерации (далее - Банком России) были разработаны рекомендации для финансовых организаций, которые призваны обеспечить информационную безопасность и минимизировать риски приостановки банковских операций в условиях распространения коронавируса.

К таким операциям относится, прежде всего, проведение денежных переводов, открытие и ведение банковских счетов физических и юридических лиц, снятие наличных в банкоматах. Предлагаемые Банком России меры касаются, в том числе, организации работы сотрудников банков вне зависимости от того, работают они удаленно или присутствуют в физически на рабочем месте.

Банковские операции, не связанные с открытием и ведением счетов и не влияющие на бесперебойность транзакций, рекомендуется производить в режиме удаленного мобильного доступа.

Банк России также обратил особое внимание на необходимость оперативного информационного взаимодействия финансовых организаций с мегарегулятором. Для этого используется автоматизированная система обработки инцидентов Центра мониторинга и реагирования на компьютерные атаки в кредитно-финансовой сфере. Ключевую ставку было решено оставить на преж- 
нем уровне - 6\% годовых, что позволит сдержать ослабление рубля и сохранить низкую инфляцию.

Для большинства компаний и индивидуальных предпринимателей важны меры по налоговым каникулам и отсрочке. Государство не предлагает освобождение всех компаний от налоговых платежей, однако предприниматели сможет получить отсрочку по выплатам на один квартал. Освобождение от некоторых видов налогов предусмотрено только для компаний в сфере туризма и авиаперевозок, которые больше всего пострадали от запретов и ограничений из-за коронавируса.

Правительство Российской Федерации утвердило Правила предоставления в 2020 году из федерального бюджета субсидий российским организациям воздушного транспорта на возмещение затрат, понесенных при выполнении мероприятий по вывозу граждан из иностранных государств, в которых сложилась неблагоприятная ситуация, связанная с распространением новой коронавирусной инфекции [4]. За счет государства будут частично возмещены убытки авиакомпаниям и туроператорам, если им пришлось принимать невозвратные билеты. Механизм выплаты компенсации пока не определен. На финансовую поддержку от государства могут рассчитывать и спортивные организации, которые столкнулись с оттоком посетителей.

Мораторий на возбуждение дел о банкротстве по заявлениям, подаваемым кредиторами, может ввести Правительство Российской Федерации. Это возможно в случае чрезвычайной ситуации, существенном изменении курса рубля и подобных обстоятельствах [5].

Правительство Российской Федерации определяет срок действия моратория и период его продления [6]. Во время действия моратория происходит приостановление исполнительного производства, в том числе по вопросам имущественного характера. Приостановлена подача заявлений о банкротстве.

Кроме того, налогоплательщики туристической, авиационной, а также иных пострадавших отраслей смогут заключить мировые соглашения в делах о банкротстве либо получить отсрочку по налогам и страховым взносам.

Правительство Российской Федерации с 6 апреля ввело на полгода мораторий на возбуждение дел о банкротстве по заявлению кредиторов. Мораторий вводится в отношении некоторых категорий должников [5]:

- организаций и ИП, у которых код основного вида деятельности включен в список отраслей, наиболее пострадавших из-за распространения но- вой коронавирусной инфекции и по состоянию на 1 марта 2020 года указан в ЕГРЮЛ или в ЕГРИП;

- организаций, включенных в перечень системообразующих организаций, утвержденный протоколом заседания Правительственной комиссии по повышению устойчивости развития российской экономики от 20 марта 2020 года № 3;

- организаций, включенных в перечень стратегических предприятий и стратегических акционерных обществ, утвержденный Указом Президента Российской Федерации от 4 августа 2004 года № 1009 [7];

- организаций, включенных в перечень стратегических организаций, а также федеральных органов исполнительной власти, обеспечивающих реализацию единой государственной политики в отраслях экономики, в которых осуществляют деятельность эти организации, утвержденный Распоряжением Правительства Российской Федерации от 20 августа 2009 года № 1226-р [8].

ФНС России разработала специальный сервис. С его помощью можно узнать, относится ли организация или ИП к числу лиц, в отношении которых введен мораторий.

Отсрочка по оплате аренды на срок до 3-х месяцев коснется только арендаторов на государственных и муниципальных объектах. В Москве и Санкт-Петербурге таких арендаторов достаточно много, тогда как в регионах их значительно меньше. Для частных объектов государство льгот не предусматривает.

Рассматривается вероятность субсидирования банковских процентов по кредитам для застройщиков, если они взяли кредиты под строительство, однако из-за пандемии коронавируса столкнулись со снижением темпов продаж квартир. Ситуацию на рынке долевого строительства будет мониторить Банк России, поэтому вопрос о льготах пока открыт.

Правительством РФ разработан специальный антикризисный план и некоторые его положения уже вступили в силу и действуют на территории РФ.

Так с 1 апреля 2020 год снижен размер страховых взносов для бизнеса с 30 до 15\%. По прогнозам аналитиков, такая мера может привести к существенным потерям всех трех фондов (порядка 350 млрд. руб.).

3 апреля 2020 года Правительством РФ утвержден список отраслей, наиболее пострадавших от пандемии коронавируса. Организации и индивидуальные предприниматели, занятые в этих сферах по основному виду экономической деятельности, получат первоочередную адресную поддержку. В этот список попали: 
- Авиаперевозки, аэропортовая деятельность, автоперевозки

- Культура, организация досуга и развлечений

- Физкультурно-оздоровительная деятельность и спорт

- Турагентства и сфера туризма

- Гостиничный бизнес

Общественное питание

Организации дополнительного образования

Организация конференций и выставок

- Бытовые услуги (ремонт, стирка, химчистка, услуги парикмахерских и салонов красоты, ремонт компьютеров)

По 30 апреля 2020 года Банк России продолжит ежедневно (за исключением календарных выходных дней) осуществлять операции по предоставлению и абсорбированию ликвидности, а также сделки на внутреннем валютном рынке [9].

Кроме того, Банк России в объявленные Президентом Российской Федерации нерабочие дни, за исключением нерабочих выходных и праздничных дней, устанавливает официальные курсы иностранных валют по отношению к рублю без обязательства Банка России покупать или продавать указанные валюты по установленному официальному курсу.

Почти все сферы экономики терпят убытки из-за ограничений и запретов во время коронавируса. Чтобы не допустить банкротство предприятий, оказавших- ся в тяжелой финансовой ситуации, Президент России объявил мораторий на 6 месяцев для этой процедуры. Кредиторы не смогут обращаться в арбитраж и банкротить предприятия, даже если по всем признакам они являются несостоятельными. Мораторий на банкротство предприятий положительно скажется и на рядовых гражданах. В период банкротства неизбежно проходят массовые сокращения и увольнения, а действующему персоналу могут задерживать зарплату. Новая мера поддержки, предложенная Президентом России, смягчит последствия экономического кризиса, даст возможность предприятию приступить к нормальной деятельности или закрыть на относительно благоприятных условиях.

Анализирую проводимые государством меры, можно сделать вывод, что государство старается поддерживать как население, оказавшееся в сложной ситуации, так и субъекты предпринимательства, попавшие в не менее худшее положение.

Дальнейшее развитие этих мер будет зависеть от ситуации. Если предположить, что все будет складываться благоприятно, то необходимость в поддерживающих мерах будет ощущаться, но скорее не как в новых, а в грамотном и наиболее полном осуществлении уже предпринятых мер. Да и вряд ли при таком исходе будут приниматься новые поддерживающие меры. Но если ситуация будет разворачиваться в противоположную сторону, то принятие новых мер, будет просто необходимо, чтобы попытаться стабилизировать финансовую ситуацию в государстве.

\section{ЛИТЕРАТУРА}

1. Официальный сайт Президента Российской Федерации. Перечень поручений по итогам обращения Президента в связи с распространением коронавирусной инфекции на территории страны (утв. Президентом Российской Федерации 29 марта 2020 года) // [Электронный ресурс] Режим доступа: http://www. kremlin.ru/acts/assignments/orders/63080 (дата обращения: 03.04 .2020 г.)

2. Федеральный закон от 03.04.2020 г. № 106-Ф3 «0 внесении изменений в Федеральный закон «0 Центральном банке Российской Федерации (Банке России)» и отдельные законодательные акты Российской Федерации в части особенностей изменения условий кредитного договора, договора займа // Российская газета.— 2020.—№ 73.

3. Постановление Правительства Российской Федерации от 2 апреля 2020 года № 422 «0б утверждении Правил предоставления субсидий из федерального бюджета российским кредитным организациям на возмещение недополученных ими доходов по кредитам, выданным в 2020 году субъектам малого и среднего предпринимательства на неотложные нужды для поддержки и сохранения занятости» // [Электронный ресурс] Режим доступа: https://www. garant.ru/files/2/3/1343632/1343632.rtf (дата обращения: 10.04.2020 г.)

4. Постановление Правительства Российской Федерации от 9 апреля 2020 года № 466 «06 утверждении Правил предоставления в 2020 году из федерального бюджета субсидий российским организациям воздушного транспорта на возмещение затрат, понесенных при выполнении мероприятий по вывозу граждан из иностранных государств, в которых сложилась неблагоприятная ситуация, связанная с распространением новой коронавирусной инфекции» // [Электронный ресурс] Режим доступа: http://www.consultant.ru/cons/cgi/online.cgi?req=doc\&base=LAW\&n=349996\&fld=134\&dst=1000000001,0 \&rnd=0.4709510338243227\#0463266532862623 (дата обращения: 07.04 .2020 г.)

5. Федеральный закон от 01.04.2020 N98-Ф3 «0 внесении изменений в отдельные законодательные акты Российской Федерации по вопросам предупреждения и ликвидации чрезвычайных ситуаций» // Российская газета.— 2020.- № 72.

6. Постановление Правительства Российской Федерации от 3 апреля 2020 года № 428 « введении моратория на возбуждение дел 0 банкротстве по заявлению кредиторов в отношении отдельных должников» // [Электронный ресурс] Режим доступа: http://government.ru/docs/39372/ (дата обращения: 07.04 .2020 г.) 
7. Указ Президента Российской Федерации от 4 августа 2004 года № 1009 «0б утверждении перечня стратегических предпринятый и стратегических акционерных обществ» // С РФ.— 2004.— № 32.— - с. 3313.

8. Распоряжение Правительства Российской Федерации от 20 августа 2009 года № 1226-р «06 утверждении перечня стратегических организаций, а также федеральных органов исполнительной власти, обеспечивающих реализацию единой государственной политики в отраслях экономики, в которых осуществляют деятельность эти организации» // СЗ РФ. — 2009. — № 35.— Ст. 4288.

9. Указание Банка России от 3 апреля 2020 года № 5428-У // Вестник Банка России. — 2020.— № 27.

○ Терехова Валентина Владимировна ( wsamoilova@mail.ru ).

Журнал «Современная наука: актуальные проблемы теории и практики»

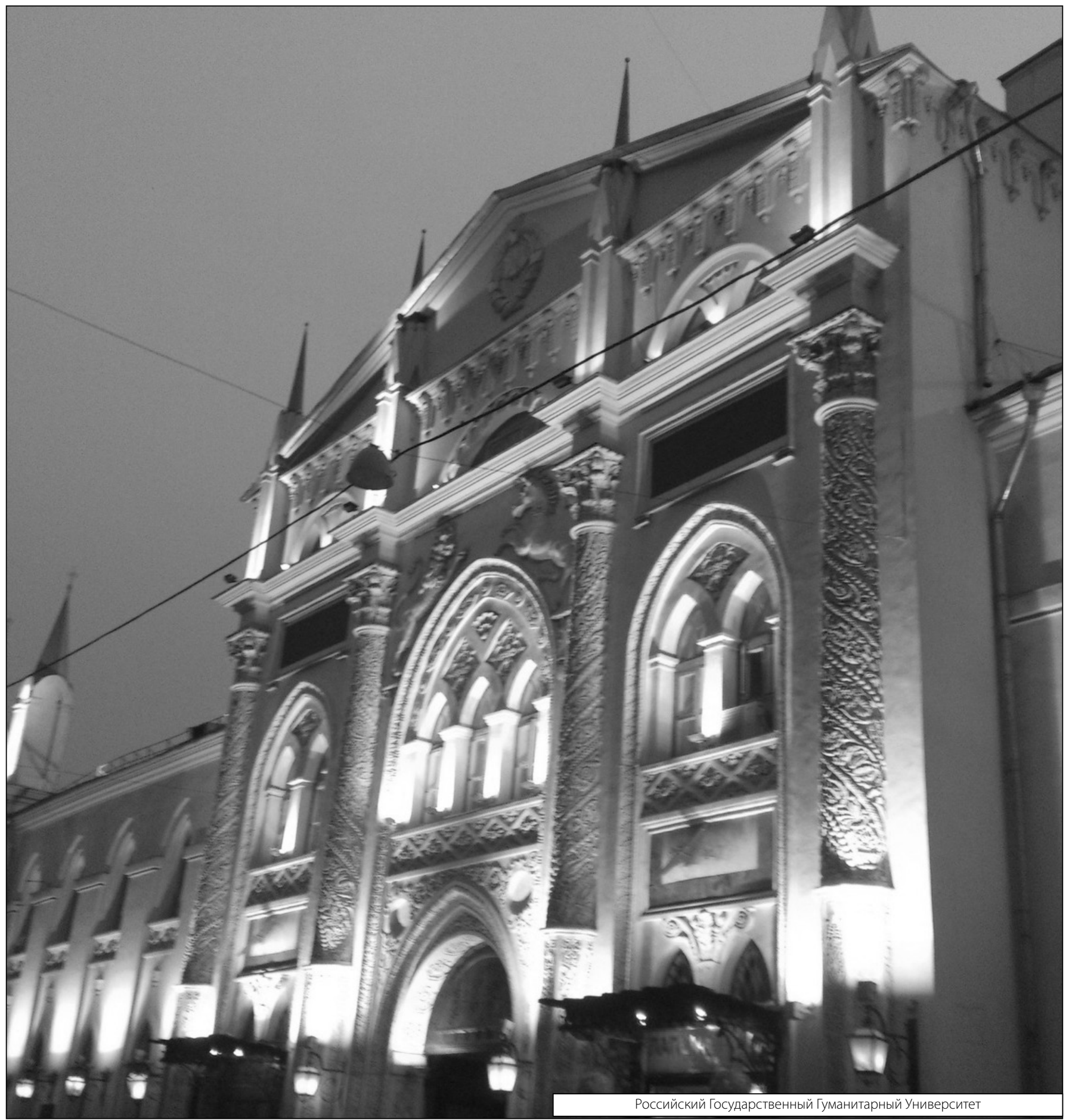

